Lexis Vol. XLV (1) 2021: 317-346

\title{
Biografía y ficción: la novela El rey de Sierra Morena, de Manuel Fernández y González (1874)*
}

\author{
Javier Muñoz de Morales Galiana \\ https://orcid.org/0000-0002-4988-9280 \\ Universidad de Cádiz \\ Javier.munozdemorales@uca.es
}

\section{RESUMEN}

Al final de El rey de Sierra Morena (1874), Fernández y González declara que su principal fuente fue lo contado por un miembro de la cuadrilla del "Tempranillo", "el Veneno". El objetivo de este trabajo es comprobar cuánto hay de ficción y cuánto de realidad en dicho testimonio, así como dilucidar qué imagen del "Tempranillo" había podido trasladarse de la tradición oral al folletín. Para ello se ha realizado un cotejo entre la novela y la biografía del "Veneno" histórico, y hemos comprobado que este había sido ejecutado sin poder sobrevivir para contarle a nuestro autor nada sobre el "Tempranillo", cuya imagen ofrecida resulta más positiva que la habida en obras anteriores con las que la hemos cotejado.

Palabras clave: Tempranillo, José María Hinojosa Corbacho, bandolerismo, biografía

\footnotetext{
"Este artículo es uno de los resultados del proyecto de investigación "Leer y escribir la nación: mitos e imaginarios literarios de España (1831-1879)” —LEyENMIESXIX—, financiado por AEI/FEDER, UE, con referencia FFI2017-82177-P.
} 
Biography and Fiction: The Novel El rey de Sierra Morena, by Manuel Fernández y González (1874)

\begin{abstract}
At the end of El rey de Sierra Morena (1874), Fernández y González declares that their main source was that was told by a member of the "Tempranillo" gang, "el Veneno". The objective of this work is to verify how much fiction there is and how much reality in this testimony, as well as to elucidate which image of "el Tempranillo" had been able to be transferred from oral tradition to the serial novel. For this, a comparison has been made between the novel and the biography of the historical "Veneno", and we have verified that it had been executed without being able to survive to tell our author anything about the "Tempranillo", whose image offered is more positive than the from previous works with which we have compared Keywords: Tempranillo, José María Hinojosa Corbacho, banditry, biography
\end{abstract}

\title{
1. Fernández y González, los bandoleros y la tradición oral
}

Manuel Fernández y González (1821-1888), aunque actualmente casi olvidado, fue uno de los novelistas más leídos, admirados y vendidos a lo largo de la España decimonónica. Se dedicó en origen a la novela histórica, que había tenido amplio desarrollo durante el Romanticismo, pero utilizando también en este caso las técnicas propias de la novela de folletín, dado que siempre publicó por entregas, bien a modo de cuadernillos sueltos, bien en los folletines de los periódicos propiamente dichos ${ }^{1}$.

Nos consta que llegó a publicar, al menos, casi doscientas novelas (Ferreras 1979: 150-154), y que llegó a granjearse la admiración de

\footnotetext{
Para la diferencia entre los distintos tipos de novela por entregas, véase Monguió (1951) y Romero Tobar (1976: 56).
} 
autores como Pérez Galdós², Vicente Blasco Ibáñez ${ }^{3}$ o Manuel Machado $^{4}$ a pesar de los desniveles en la calidad literaria de sus obras. En un principio, estas trataban sobre cuestiones históricas inspiradas en tiempos muy remotos, por lo general en la Edad Media o en el Siglo de Oro. Pero a lo largo de los años fue introduciendo muchas otras temáticas en su producción. A sus lectores llamó especialmente la atención que, a partir de cierto momento, con la publicación de Los siete niños de Écija (1863) ${ }^{5}$, pasara también a escribir novelas históricas protagonizadas por bandoleros famosos, muchos de ellos de su propio siglo 6 .

Novelizar en torno a sucesos ocurridos recientemente suponía, necesariamente, un cambio drástico en lo referente a las fuentes de inspiración. En algunas de sus novelas de ambientación medieval era muy habitual encontrar referencias a crónicas antiguas, o

2 En concreto Pérez Galdós le reconoce que "reinó sin émulos” en el género de la novela histórica y que "tiene un puesto indiscutible en las letras castellanas" del XIX (2004: 542).

3 Para Blasco Ibáñez, Fernández y González fue "el resucitador de la novela española” (1982: 97).

4 Para Manuel Machado las novelas de Fernández y González eran «encanto de la época, y aún encanto nuestro muchas de ellas» (1981: 141).

5 Ferreras señala 1855 como fecha probable para la publicación de una novela anterior sobre bandoleros, Juan Palomo o la expiación de un bandido (1979: 150). No obstante, Cruz Casado muestra ciertas dudas de que esa obra se hubiera publicado realmente en esa fecha (2015: 11). En 1864, Fernández Cuesta comentaba que en ese momento el autor estaba componiendo la novela Juan Palomo (1864: 6), por lo que entendemos que, como bien temía Cruz Casado, la fecha anotada por Ferreras era errónea.

6 Pérez Galdós comenta que Fernández y González «tuvo que recurrir a buscar las emociones en un campo distinto de la galantería romántica, de la arrogancia española y de las estupendas hazañas de los siglos XVI y XVII. Para herir la imaginación del pueblo, recurrió a proezas de los bandidos célebres, héroes de encrucijada, que por una aberración del sentimiento nacional despiertan en ciertas clases un interés malsano» (2004: 546). En la misma línea, Palacio Valdés comenta, sorprendido, lo siguiente: «Un hombre que había pasado toda su vida en el alcázar del rey tratado a cuerpo de ídem, dedicado exclusivamente a vigilar la entrada y salida de los galanes por las puertas secretas, los suspiros de la reina y las órdenes del monarca, marcha de improviso a Sierra Morena y empieza a echar el alto a los viajeros en compañía de Diego Corriente y Juan Palomo» (1878: 95-96). Para un análisis panorámico sobre las novelas de bandidos de Fernández y González y otra literatura similar, véanse los trabajos de Cruz Casado (2001) (2015). 
a historiadores de cierto prestigio como Juan de Mariana ${ }^{7}$. Pese a que sus narraciones resultaran en muchas ocasiones inverosímiles, él siempre se esforzaba por intentar que fueran creíbles aludiendo a las fuentes utilizadas, e intercalando episodios reales con otros puramente ficticios. No obstante, cuando también se adentró en el terreno de la novela sobre bandoleros, si bien no podía pretender utilizar ninguna crónica, se sirvió también de otro recurso que hasta el momento no le era lícito utilizar: la tradición oral.

En sus muchas novelas sobre el rey Pedro I el Cruel, por ejemplo, no era viable en modo alguno utilizar testimonios orales sobre los que construir una historia; ese monarca en cuestión había vivido en el siglo XIII, y evidentemente no quedaban con vida ninguno de sus contemporáneos. Pero todo cambia si hablamos de un bandolero decimonónico. Hernández Girbal, biógrafo de Fernández y González, comenta que, a fin de encontrar inspiración para sus novelas, nuestro autor "iba frecuentemente a los barrios bajos", y a las "renombradas tabernas de la calle Toledo, de la Ribera de Curtidores y otras calles no menos famosas", donde "observaba y hablaba con tipos de siniestras cataduras” (1931: 112).

Nos consta, a su vez, que al menos en una ocasión Fernández y González se jactaba de haber hablado con uno de estos sujetos siniestros. En una de sus novelas, El rey de Sierra Morena, el tema central son las aventuras del famoso bandolero José María “el Tempranillo"; la novela como tal se publicó en 1874, y el criminal en cuestión murió en 1833, pero al final de la obra afirma que se ha inspirado, fundamentalmente, en la narración oral llevada a cabo, supuestamente, por uno de los principales lugartenientes del Tempranillo, Luis de Céspedes “el Veneno": "Y aquí concluye nuestra historia, cuyas noticias debemos al estropeado don Luis de Céspedes, a quien conocimos en Madrid en una ocasión en que vino a

7 Obsérvese, por ejemplo, el comienzo de la novela El condestable don Álvaro de Luna (1851). 
causa de un pleito que tenía en el tribunal supremo" (Fernández y González 1874: v. 5, 856) ${ }^{8}$.

Tal declaración al final de la novela vendría a vincularla con la literatura oral, por suponer en su totalidad, al menos presuntamente, una reelaboración del testimonio que Luis de Céspedes le habría proporcionado a nuestro autor en una de sus "correrías" en busca de narraciones interesantes que poder plasmar más adelante en sus obras. Sin embargo, resulta inverosímil la posibilidad de que la narración en su totalidad provenga de lo que el "Veneno" le pudo llegar a contar a Fernández y González. La novela, como tal, es excesivamente extensa, llegando incluso a los cinco volúmenes; $y$, como solía ser habitual en la narrativa por entregas, la trama principal está notoriamente engrosada con numerosos sucesos secundarios que no aportan demasiado al argumento. Es muy probable, por ello, que, aunque partiera de una serie de sucesos relatados realmente por un informante en Madrid, nuestro autor los haya reelaborado y ampliado con muchos otros de invención propia.

\section{La historia de Luis de Céspedes, el teniente "Veneno": del testimonio oral a la literatura escrita}

No obstante, si atendemos estrictamente a todo lo narrado en la novela con relación a Luis de Céspedes "el Veneno", sería hasta cierto punto viable reconstruir, aunque con cierto margen de error, la historia que este individuo le habría transmitido oralmente a nuestro escritor en Madrid. Bien es cierto, por otra parte, que el título de la novela no hace referencia a este bandolero, sino a su respectivo jefe, José María “el Tempranillo”; tengamos en cuenta que esa otra figura era mucho más famosa, y que nuestro autor bien podía usarla de reclamo para obtener más lectores. Pero en esta novela el verdadero hilo conductor es la historia del "Veneno", y su relación con el bandolero que da título a la obra; la imagen ofrecida de este

\footnotetext{
8 Todas las citas de El rey de Sierra Morena habidas en este trabajo provienen de esa misma edición.
} 
último parte, sobre todo, del punto de vista del protagonista real. La novela, de hecho, se inicia al poco de alistarse Luis de Céspedes en los "migueletes", esto es, un cuerpo paramilitar financiado por el gobierno para recorrer la sierra en busca de bandoleros (v. 1, 3-4).

El lector no tarda en descubrir que el objetivo de este teniente, como miguelete, es capturar a José María: "no me puedo detener porque, como quien dice, vamos ya a la cola del caballo de José María” (v. 1, 5). Pero su motivación real no tiene nada que ver con el respeto a la justicia, sino con la sed de aventuras de este personaje: "Si era miguelete, consistía en que le gustaban las aventuras. Si no hubiera podido ser miguelete, se hubiera hecho caballista para dar pasto a la actividad a la fiereza de su alma” (v. 1, 99-100). No hay, por tanto, nada que ate a Luis de Céspedes a la obediencia a la ley; por el contrario, desde un inicio se nos da a entender que podría inclinarse hacia el bandidaje con tal de poder seguir llevando una vida aventurera.

En su camino, de hecho, muy pronto encuentra algo que lo desvía de su principal presa, y es que se enamora de una mujer llamada María, aunque conocida más bien con el sobrenombre de Rubia del Valle; al verla, "se puso densamente pálido y se estremeció” (v. 1, 99), y muy pronto se dirige a ella reclamándola amorosamente: “y lo que es yo, tiro el gambeto y la charretera en cuanto usted me diga que me quiere, y me caso con usted en el santuario de la Virgen del Torrente, y luego la pongo a usted en las ancas de un bicho, y me la llevo a usted a mi casa de Sevilla a que mande usted en mí” (v. 1, 101). Esto da lugar a un triángulo amoroso y a uno de los principales conflictos con los que se inicia la novela, y es que esa mujer resulta estar enamorada de otro hombre cuya identidad, en un principio, no se revela (v. 1, 102-107).

El teniente Veneno, al ver que no tiene posibilidades con su amada María, decide comprometerse al menos a ayudarla a que pueda casarse con el hombre al que ama, amor que al parecer tampoco es correspondido. No obstante, la trama se complica más aun en tanto que ese sujeto resulta ser, aunque Luis de Céspedes aún no lo sepa, nada menos que el Tempranillo, su principal objetivo: 
"(María) Temblaba de que llegase un día en el que el teniente pudiese descubrir que era José María el hombre a quien ella amaba" (v. 1, 109). Tal como ella teme, el propio teniente Veneno no tarda en descubrir la verdad; es precisamente el tío Pitarrecio, padre de María, quien se lo revela: "La Rubia del Valle está echando el alma por un lado por el señor José María. ¿Pero a usted qué se le da de esto, si el señor José María no la quiere a ella?” (v. 1, 169).

Justo después, Luis de Céspedes descubre también la identidad de la mujer amada por el Tempranillo: “ $\mathrm{S}$ Si no es hermosa que digamos, y no tiene toda la gracia de Dios, doña Consuelo, la hija del corregidor de Córdoba!” (v. 1, 170). Tiene entonces lugar el augurado encuentro entre José María y el teniente Veneno, pero a pesar de las intenciones originales del primero, nadie sale herido (v. 1, 174-175).

En este decisivo encuentro entre el teniente Veneno y su futuro jefe, el narrador nos permite intuir cierta clase de dominio natural del segundo sobre el primero; a partir de una metáfora taurina, se nos da a entender que solo José María tiene control total de la situación, y que su sola presencia basta para intimidar a quienes lo están persiguiendo. Más adelante, el Tempranillo incluso se mofa de su perseguidor, haciendo ver que en ningún momento se ha sentido en peligro por su culpa: "usted anda detrás de mí y yo le huelo, y por quemarle a usted la sangre, y porque usted se vuelva loco, en vez de ir usted detrás de mí, yo voy detrás de usted, y me divierto en verle a usted despeándose y registrando barrancos" (v. 1, 177).

Con todo, el carisma y el carácter afable y desenfadado de José María terminan por seducir a Veneno; después de prometerle su amistad, ambos acaban siendo cómplices en el mismo crimen, a pesar de que Luis de Céspedes quisiera en un momento detener al bandido: "Y he aquí al teniente Veneno haciéndose cómplice de un robo precedido de muerte, echando mano a un cuerpo de delito, y ayudando al bandido a sacarle fuera del hoyo que había hecho" (v. $1,178)$.

La lealtad de nuestro protagonista para con el cuerpo de migueletes queda entonces comprometida. Consciente de ello, José María 
se jacta al respecto y le procura hacer ver que no tiene más salida que la deserción: “¿Pues por qué vive usted con su partidilla de doce migueletes, sino porque a mí me da la gana, hombre? Y porque aunque usted no lo crea, usted me gusta. Vaya, compadrito, que usted va a ser mi teniente, y cuando yo se lo digo a usted es porque yo lo sé” (v. 1, 180).

El título del capítulo XIV ya advierte cuál va a ser el resultado de todo ello: "De cómo el teniente Veneno dejó de ser teniente de migueletes para ser teniente de ladrones” (v. 1, 183). José María vuelve a mostrarse de manera amistosa con respecto a nuestro protagonista, insistiendo en ser su amigo a pesar de la enemistad original: “-Si usted cree —contestó José María- que hemos venido aquí para reñir, se equivoca usted, porque yo no riño nunca con amigos; yo he venido aquí para que usted se venga conmigo" (v. 1, 184). Finalmente, Luis de Céspedes acaba cediendo y uniéndose al Tempranillo (v. 1, 188-189).

De este modo, una persona como Luis de Céspedes, nacida originalmente en una familia acomodada, y que en un principio servía al gobierno motivado únicamente por su sed de aventura, acaba cayendo en la ilegalidad y la marginación social, todo ello por la “afición”, esto es, apego hacia una vida emocionante por encima de las comodidades que podría proporcionar, por ejemplo, el dinero; el propio José María afirma que no es por avaricia el dedicarse al bandidaje, sino por amor a esa clase de vida.

A partir de aquí, las aventuras del Tempranillo y del Veneno corren parejas en las páginas - y volúmenes - restantes; la trama, por ello, se diluye en numerosos pasajes de importancia relativa y estructurados sin otro propósito que el de la acumulación. Pero la vida del protagonista sigue siendo relatada, aunque "a trompicones"; el narrador no se priva en dar cuenta de los principales hitos que lo arrastraron desde ese inicio en la delincuencia, embelesado por el entusiasmo aventurero de la juventud, hasta llegar a una adultez en la que nuestro autor en persona habría podido conocerlo muy "desmejorado" en Madrid, ciudad en la que tendría que resolver un pleito. 
El siguiente hito en la vida de este personaje desde el momento en el que entra a servir a José María, no obstante, pasa por resolver lo tocante a su amor hacia María "la Macandita", también conocida como la "Rubia del Valle"; su relación con esta mujer será, de hecho, lo que vertebre el resto de los acontecimientos relatados en la novela. Desde un primer momento queda claro que el Tempranillo no tiene ninguna clase de interés amoroso hacia ella, pero cuando descubre los sentimientos de su nuevo subordinado, menos aun; de hecho, promete ayudarle al respecto porque empatiza con su situación (v. 1, 195-196).

De esta manera, José María le promete un futuro próspero en todos los aspectos imaginables; no solo conseguir casarse con la mujer amada, sino también una tregua por parte del rey que les permita dejar de vivir en la ilegalidad, pero seguir manteniendo su poder en la zona de Sierra Morena hasta poder seguir siendo considerados los "reyes" de Andalucía. Un estilo de vida utópico e irreal, que, como más adelante veremos, será imposible de realizar; en cualquier caso, el Tempranillo sí que logra llevar a buen puerto lo prometido con relación a María. De hecho, ella misma ya había empezado a sentir cambios en sus inclinaciones con relación a José María y al Veneno. En un fragmento (v. 1, 220-221) podemos apreciar que realmente María no estaba tanto enamorada de José María como tal, sino de algunas de sus características; en concreto, las relativas a la virilidad que le es atribuida en tanto que bandolero y hombre "dispuesto a todo". Cuando el teniente Veneno comienza a llevar una vida igualmente delictiva, y cuando comete igualmente sus primeras "fechorías", la impresión que causa sobre la Macandita cambia, y esta empieza a contemplarlo con otros ojos.

Para contribuir a esta inclinación de sentimientos, el propio José María trata de convencer a la Rubia del Valle y hacerle ver a esta que el teniente Veneno es alguien aun más deseable que él mismo: "Pues bien; el teniente Veneno es más valiente que yo” (v. 1, 250). Además de ello, el Tempranillo no se priva de intentar enfurecerla a fin de que olvide sus sentimientos amorosos originales (v. 1, 252). 
Excitada la soberbia de María, parece estar dispuesta para corresponder los amores del teniente Veneno, no sin que antes tenga lugar un último episodio de carácter altamente emotivo. Luis de Céspedes no tiene del todo claro hasta qué punto sus amores son correspondidos o no, pero incapaz de aceptar una negativa, amenaza a su amada con suicidarse con tal de que ella acceda a sus pretensiones (v. 1, 521-526).

De esta manera, por violenta que sea y por mucho chantaje emocional que implique, comienza la relación amorosa entre Veneno y María la Macandita, que no deja de tener innumerables tropiezos; de entrada, la familia de la Rubia del Valle descubre que Luis de Céspedes es hasta cierto punto mujeriego, y que difícilmente podría mantener una palabra de fidelidad: "El teniente Veneno le ha pedido a Colás el Macandito por mujer a su hija la Rubia del Valle, y [...] Colás el Macandito se ha echado a husmear si había moros en la costa, y se ha venido a rondar por aquí; y ha descubierto que el teniente Veneno tenía amores antiguos; y muy comprometidos" (v. 2, 293-294).

El asunto se vuelve especialmente delicado cuando se descubre que Luis de Céspedes ha ido más allá de la sola infidelidad, y que ha llegado incluso a casarse con su anterior amante después de dejarla embarazada y de que esta tenga un hijo suyo: "Clara había dado a luz en la torre del Alma en Pena a una criatura. Y como aquella criatura era hija del teniente Veneno, y el teniente Veneno amaba a Clara, le costó muy poco trabajo al padre Anastasio decidirle a que se casara con ella" (v. 2, 350).

Pero el autor logra plantear un nuevo lance que reavive en el teniente Veneno sus amores por la Macandita; una de las muchas aventuras que alargan la trama principal consiste en el secuestro de esta por otro bandido, el Hermano de la Campanilla, momento en el que Luis de Céspedes tiene que replantearse sus sentimientos; se menciona, así, que estaba "dado a los diablos" y que "se enfurecía cuando consideraba que el monstruoso Hermano de la Campanilla estaba en posesión, siquiera fuese por la fuerza, de la Rubia del Valle” (v. 2, 351). 
La psicología de este personaje funciona mediante la valoración de todo lo que le resulta inaccesible. Cuando no tenía claro si sus amores podían ser correspondidos, amenaza incluso con suicidarse; del mismo modo, siente una rabia atroz cuando María deja de estar dentro de su alcance por el secuestro. Sin embargo, ni él ni ninguno de los hombres de José María logran rescatarla en una primera instancia. Es entonces cuando otros de los subalternos del Tempranillo, el Visojo, decide encargarse él mismo del asunto, para poder ocupar una posición más destacada en la organización: "Yo le he oído al señor José María quejarse y lastimarse de la suerte de esa pobre muchacha, $[\ldots]$ y decir que si cogía al Hermano de la Campanilla lo iba a hacer pedazos, [...] pero si todos juntos no hemos podido cogerle, ¿por qué no le he de coger yo solo?” (v. 3, 140). Este otro bandolero sí que logra llevar a buen puerto su cometido (v. 3, 178).

Haber sido rescatada por este hombre, y no por el teniente Veneno, hará que María le reserve al Visojo una admiración que ni siquiera le estuvo destinada a su anterior novio, a quien de hecho pasará a despreciar delante de su nuevo salvador. La consecuencia de esto no puede ser más predecible, esto es, que el Visojo se enamore de ella (v. 3, 182).

Todo ello parece ser, precisamente, intención deliberada de María, no porque sienta nada hacia este bandido, sino porque es consciente de que lo puede utilizar: "María había alcanzado su objeto. Comprendió que el bandido era completamente suyo" (v. 3,183 ). Poco después se revela el verdadero objetivo de esta mujer, esto es, utilizar al Visojo para alzarse ella misma como bandolera, al margen -e incluso en contra- de José María y del Veneno: "Lo primero que vamos a hacer es comprar para mí un vestido de hombre y armarme, y un caballo, y vamos a levantar una partida, ¿sabe usted? Y hacer tantas atrocidades, que José María se muera de vergüenza” (v. 3, 192).

Como bandolera, María no tarda en adquirir fama tal que pueda ensombrecer al propio Tempranillo: "Pues mire usted que ha echado una fama el angelito, que si quieres: ha dejado pequeño 
hasta a su compadre de usted José María” (v. 3, 268). Este conflicto habrá de culminar con el encuentro de Veneno con su anterior novia, entregada esta última al crimen, y sumida en ansias de venganza; finalmente, los antiguos amantes se reencuentran y tienen un enfrentamiento que no puede sino finalizar con la reconciliación (v. 3, 366-367).

Resuelto este conflicto, la vida del protagonista parece alcanzar un mínimo de estabilidad al restablecerse su relación con su novia original; esa prosperidad se acentúa aun más cuando poco después el Tempranillo consigue un indulto, por parte de Fernando VII, para toda su banda, según el cual pasarían de ser bandoleros a ser una patrulla al servicio del rey, cuyo objetivo sería recorrer la sierra en busca de otros criminales: "-Se me propone convertirme en perro de presa con collarín del rey; bueno — dijo José María-, pero yo me he puesto ya al servicio de su majestad y nada tengo que decir" (v. 3, 483). De este modo, Veneno pasa a tener ya no solo una relación estable con la mujer a la que ama, sino que también deja de estar fuera de la ley, y vuelve a ser, como cuando estaba con los migueletes, un leal siervo al servicio de Fernando VII.

A partir de aquí, y sobre todo en los dos últimos tomos, la novela queda engrosada con otro sinfín de aventuras relativas a lo que les acaeció a los personajes mientras servían al rey; una de ellas, por ejemplo, pasa por narrar una visita de José María a Madrid para tratar con el monarca, así como los amoríos que el bandolero presuntamente tuvo en la capital. La trama, por ello, se diluye cada vez más, si bien sigue habiendo un arco argumental que pasa a ser el más relevante, esto es, la enemistad de la banda con José María “el Barberillo", un peligroso criminal al que intentan atrapar por todos los medios. Sin embargo, este otro bandolero es quien acaba dando muerte al Tempranillo (v. 5, 163-164).

Muerto José María, el teniente Veneno pasa a ser su heredero, y el nuevo líder de su escuadrón; adquiere así una enorme responsabilidad, ya no solo para con sus compañeros - entre los que se encuentra su amada María-, sino también para con el rey de España y con el estado, por el deber civil que supone estar al mando 
de un escuadrón ya no de bandoleros, sino dedicado precisamente a limpiar la sierra de malhechores. No obstante, Luis de Céspedes no demuestra estar a la altura de absolutamente nada de lo que se espera de él, sino que comete todos los errores imaginables: vuelve a serle infiel a María al enamorarse de otra mujer llamada "Milagros", quien resulta ser, en realidad, el Barberillo disfrazado (v. 5, 729).

No obstante, quien finalmente logra dar con el Barberillo no es Veneno, sino Consuelo, la esposa de José María, que tras atraparlo lo manda asesinar: “-Arrojadle —exclamó Consuelo. El Barberillo fue lanzado. Por algunos momentos, a causa del impulso, el cuerpo del miserable se balanceó de una manera violenta.” (v. 5, 829). Luis de Céspedes, sin embargo, sigue pretendiendo llevar a buen puerto la labor encomendada a su escuadrón, por lo que trata de perseguir a otro malhechor llamado Melgarejo, que había asesinado a otro miembro de la banda de Veneno, el tío Pedernales. Sin embargo, en el proceso recibe un disparo, y para poder ser curado tienen que amputarle un brazo y una pierna (v. 5, 855-856).

A renglón seguido se introduce el último párrafo de la obra, ya citado anteriormente, y de esta manera concluye la narración. El teniente Veneno, después de llevar una vida licenciosa y llena de tropelías, en la que ni servir al estado ni su relación con María lo motivan a estabilizarse del todo, finalmente es mutilado e incapacitado para seguir comportándose de esa manera; solo entonces decide "convertirse" y mantenerse fiel a su esposa.

\section{La biografía del teniente Veneno: ficción y realidad}

Tras haber omitido todos los sucesos secundarios narrados en esta larguísima novela de cinco tomos, nos hemos ceñido únicamente a lo relativo a la vida de Luis de Céspedes, y de por sí resulta demasiado agitada y pintoresca como para cuestionar su credibilidad. Es, fundamentalmente, la historia de una persona que pasa de miguelete a bandolero motivado sobre todo por el amor, pero resulta demasiado impulsivo para poder ser fiel. Lances como el de Veneno enfrentándose a su mujer después de convertirse esta última en una 
bandolera parecen, desde luego, más propios de una obra de ficción que de la biografía real de un individuo.

Aunque pueda haber elementos reales en el relato, es prácticamente asegurable que otros tantos deben ser invención, si no del propio Fernández y González, quizá sí de su informante. Desde luego, si cotejamos los datos con la bibliografía actual, encontramos flagrantes contradicciones. Joaquín Guichot, en su Historia del Ayuntamiento de Sevilla, hace alusión al indulto que el rey dio al Tempranillo y a su cuadrilla, y comenta que fueron "indultados todos los bandidos, a excepción del famoso José Rojas, "Veneno", que, juzgado y sentenciado por la comisión ejecutiva militar de la provincia, fue muerto en garrote vil el 13 de Diciembre (sic) de 1832, descuartizado y repartidos sus despojos en las inmediaciones", citado por Quirós y Pérez (1992: 20-21)9. López-Burgos del Barrio, además, da crédito a uno de los testigos que presenciaron esa ejecución: "Richard Ford unía su miedo a una irresistible atracción por los bandoleros personalizados estos en la figura de José María "El Tempranillo", llegando a presenciar en Sevilla la ejecución de José de Rojas El Veneno, un integrante de su banda" (2012: 45). Si nos remitimos al texto original de Richard Ford, publicado en 1846, vemos que de hecho refiere con detalle dicha ejecución:

An account of the judicial death of one of the gang of José María, which we witnessed, will be an appropriate conclusion to these remarks, and an act of justice towards our fair renders for this details of breaches of the peace, and the bad company into which they have been introduced. Jose de Roxas, commonly called (for they generally have some nickname) El Veneno, "Poison" from his viper-like qualities, and when brought to the ground by a ball in his leg, killed the soldier who rushed forward to secure him. He proposed when in prison to deliver up his comrades if his own life were guaranteed to him. The offer was accepted, and he was sent out with a sufficient force; and such was the terror of his name, that they surrended

\footnotetext{
9 Ese mismo autor previamente también había hecho alusión a la ejecución de Veneno en un trabajo anterior (Quirós y Pérez, y Ardilla 1973: 118); a partir de ahí, también Álvarez Barrientos y García Mouton consideran veraz esa ejecución (1986: 50).
} 
themselves, not however to him, and were pardoned. Veneno was then tried for his previous offences, found guilty, and condemned (Ford 1846: 206-207).

Contamos, por tanto, con numerosa bibliografía que corrobora la muerte del Veneno en el 32, antes de que falleciera el propio Tempranillo, pero también tenemos el testimonio de alguien que pudo presenciarlo. Por otra parte, ninguno de estos textos hace alusión a "Luis de Céspedes", nombre que no parece corresponderse al del "Veneno" real, sino a "José de Rojas”, que sí parece ser el auténtico nombre de pila que tuvo este bandolero.

La narración de Fernández y González, por tanto, parece ser errónea en prácticamente su totalidad. Está equivocado tanto el nombre como la fecha en la que el sujeto en cuestión murió; por otra parte, si el Veneno real había sido descuartizado en 1832, cuando nuestro autor contaba tan solo once años, resulta del todo inverosímil que hubiera podido entrevistarse con él en algún momento en el que el bandido fuera ya mayor y desmejorado, y se dirigiera a resolver un pleito a Madrid.

Entendemos, por tanto, que los hechos narrados en la obra, que han sido sintetizados en el apartado anterior, son del todo ficticios, y que no tienen por qué corresponderse con ningún referente histórico o real; no obstante, ¿ realmente podemos culpar de todo ello al propio Fernández y González, o más bien a su informante? La novela en su totalidad, con sus cinco extensísimos tomos, parece desde luego deliberadamente alargada hasta el enrevesamiento más folletinesco por nuestro autor, pero todo lo concerniente a la biografía del personaje principal pudo perfectamente haber tenido sus orígenes en la tradición oral.

Quizá no podamos plantear como real el hecho de que el teniente Veneno en persona le contara a nuestro autor todas sus aventuras, pero mucho más plausible es hablar de un impostor, de alguien que supiera del sobrenombre otorgado al lugarteniente del Tempranillo y que se lo adjudicara a sí mismo para poder fanfarronear largo y tendido y hacerse pasar por miembro de la cuadrilla de José María. Es imposible comprobar si esto tuvo lugar o si todo es producto 
de la imaginación de nuestro autor, pero desde luego esta hipótesis resulta de sobra verosímil si tenemos en cuenta su afición por frecuentar ambientes siniestros en los que charlaba con criminales y gentes de mal vivir a fin de reunir inspiración para sus obras.

Aunque actualmente podemos cotejar esta clase de datos con bibliografía especializada, en aquella época les debía resultar mucho más difícil comprobar qué cuestiones podían ser verdad o mentira en lo relativo a la vida de alguien como el Tempranillo, de quien no había, a disposición del público, nada parecido a una "biografía oficial”. Por ello, podía resultar creíble el testimonio de alguien como el presunto informante de nuestro autor, ya que tampoco había forma de comprobar si podía estar mintiendo. Es más; incluso hoy en día, en bibliografía más o menos actual, encontramos textos como el siguiente:

La fama de "El Tempranillo" comienza a crecer de manera desorbitada. Se le unen y se le subordinan hombres perseguidos por la justicia y otros, libres de crímenes, que se sienten atraídos por su valentía. Al mismo tiempo fuerza contra él una persecución constante a cargo de tropas militares enviadas por el Capitán General de Sevilla. Entre estas fuerzas figura un teniente, llamado don Luis de Céspedes, perteneciente a una noble familia sevillana, mozo aguerrido, aficionado a las mujeres y al vino y con tanta carga de valentía como de deudas. Don Luis de Céspedes se siente también atraído por la vida y la fama de José María y una noche deserta y se une al bandolero. Este no solo lo acepta, sino que después de unas pruebas de sinceridad y lealtad lo convierte en uno de sus lugartenientes. El carácter de Céspedes es tan vidrioso y duro y sus instintos tan criminales que no tarda en ser bautizado con el apodo de "Veneno" (Ortega Serrano 2010: 236-237).

Encontrar tal afirmación en un artículo relativamente actual podría dar algo de validez a lo que Fernández y González pretende exponer como real en su novela; el texto de Ortega Serrano al menos no pasa por considerar que "José de Rojas" era el llamado "Veneno" que luchó en las filas del Tempranillo, sino que en efecto "Luis de Céspedes” era su nombre real. Sin embargo, el citado artículo no 
parece demasiado fiable en este punto a juzgar por dónde ha obtenido la información referida:

Después, en el orden cronológico, hay que citar, aparte de reportajes y artículos periodísticos que no faltarían en ninguna época, el estudio de don Natalio Rivas y a continuación el de Constancio Bernaldo de Quiros y Luis Ardila (sic) “Bandolerismo Andaluz”. A ellos hay que anteponer, aunque como distinto género, la novela de Fernández y González “El Rey de Sierra Morena” (Ortega Serrano 2010: 235).

Evidentemente una novela de ficción no puede ser tenida por fuente real, ni comparada a otras históricas; como sea, justicia es mencionar que el trabajo de Ortega Serrano se titula "“El Tempranillo" (En la literatura y la leyenda)". Mucho más grave es el caso de Ávila Granados, que vuelve a referir, como si fuera real, la siguiente historia relativa a José María:

Un tal don Luis de Céspedes, teniente de migueletes, perteneciente a una noble familia sevillana, arrogante, guapo, valiente, aunque de vida nebulosa, jugador, bebedor y mujeriego, fascinado por las legendarias gestas y la nobleza de el (sic) Tempranillo, tras desertar y colgar el uniforme, se presenta ante él, solicitando un puesto en su banda. José María no dudó en aceptarle, pero lo sometió a diferentes pruebas, para saber realmente de su lealtad y arrojo; elevándole, al poco tiempo, a la categoría de teniente; lo cual encendió un cierto temor al resto de la partida, por la dureza y autoritarismo del carácter de Luis de Céspedes; por ello, no tardó en ser bautizado como el Veneno (Ávila Granados, 2008: 307).

Nuevamente reitera lo mismo que en la novela de Fernández y González, si bien en este caso su autor, al hablar de José María, se refiere a "su biógrafo el novelista Manuel Fernández y González, autor de cinco nutridos tomos de las hazañas de el (sic) Tempranillo" (Ávila Granados, 2008: 301). Nuestro autor, en este caso, es elevado a la categoría de "biógrafo" del Tempranillo, título que de ningún modo se le puede otorgar dado el carácter evidentemente ficticio de su novela. 
Como sea, es en cualquier caso disculpable el crédito que en este contexto le hayan podido otorgar a nuestro novelista dado que este se jactaba de haber contado con una fuente quizá inaccesible a muchos otros historiadores, esto es, el testimonio de uno de la cuadrilla del Tempranillo, el "Veneno". Un breve cotejo nos ha permitido comprobar lo falaz de este presunto "testimonio" dado que el hipotético informante, aparte de tener un nombre de pila diferente, llevaría muerto y descuartizado desde 1832.

En cualquier caso, si seguimos dando todo el crédito posible a Fernández y González, podemos entender esta novela como una ventana a la tradición oral de las zonas más conflictivas de Madrid en aquellos años, en las que sujetos de mal vivir fanfarroneaban jactándose de haber sido la mano derecha del Tempranillo; nuestro autor únicamente sería víctima del engaño de uno de ellos. Al margen de los acontecimientos que haya tomado directamente de su informante, la tradición oral de las clases populares y la germanía resplandece en esta obra en el empleo reiterado de léxico, expresiones y modos de hablar propios de un grupo social muy concreto; por ejemplo, y como bien podemos advertir en los fragmentos citados, la reiteración constante del vocativo "usted".

4. La imagen de José María “el Tempranillo”: de la literatura oral al folletín

Otro de los motivos por los que esta obra destaca en el contexto de la literatura oral es el de la "imagen" que aquí podemos percibir de José María “el Tempranillo”, entendiendo “imagen” en la definición de Moll, esto es, "enunciados empírico-referenciales, seleccionándolos y colocándolos bajo distintos prismas, y que simulan poseer cierta referencialidad sin que en realidad sean de naturaleza referencial" (Moll 2002: 361-362).

Es evidente que Fernández y González no pudo conocer en persona al Tempranillo; es también muy probable que su informante tampoco, o que al menos no tuviera una relación con él tan estrecha como la que mencionaba. Por ello, es lícito hablar de "imagen" a 
la hora de mencionar todo lo que estas personas creían saber sobre José María, sin que pudieran llegar a comprobarlo. El hecho de que haya un posible origen en la literatura oral, y el hecho también de que esta obra fuese tan exitosa y vendida, son motivos por los que El rey de Sierra Morena nos permite atender ya no solo a la imagen objetivada en este texto, sino también a la que pudo haber previamente y a la que posteriormente se pudo difundir con la publicación de estos cinco tomos. Debemos entender que la literatura europea ya nos había ofrecido una imagen de este personaje, por ejemplo, en Carmen de Merimée:

Me habéis hablado de José María; pues bien, allí fue donde trabé conocimiento con él. Su querida le acompañaba en las expediciones. Era una hermosa muchacha, honrada, modesta, de finos modales; jamás se le oyó una palabra mal sonante, y además sentía por José María un cariño extremado. En cambio él la hacía muy desgraciada. Siempre andaba detrás de todas las mujeres, la maltrataba, y algunas veces se le ocurría la idea de aparentar celos. Cierta vez la dio una cuchillada; pues bien, ella le quería aún más. Las mujeres, las andaluzas sobre todo, son así. Aquella estaba orgullosa de la cicatriz que tenía en el brazo y la enseñaba con satisfacción. José María, además de todo esto, era el peor de los compañeros. En una expedición que hicimos se las compuso tan bien, que se quedó el provecho, dejándonos a nosotros solo los golpes y molestias de la empresa (Merimée 1891: 25-26).

Podemos apreciar que, ante todo, la imagen que Merimée ofrece es fundamentalmente negativa; nos presenta a un José María puramente salvaje, pero de la peor manera imaginable; un bandido que no solamente es violento, sino que también es cruel, y se comporta con sadismo incluso con las personas que le son más allegadas, especialmente con las mujeres. La visión que, en cambio, Fernández y González nos ofrece, será muy diferente; pero para comprenderla debemos atender a lo siguiente:

Es difícil encontrar algún autor español que, a mediados del siglo XIX, no se quejara en alguna ocasión de lo que consideraba caracterizaciones erróneas, caricaturescas o capciosas de España. 
Escritores y artistas limaron asperezas cuando se trató de responder a las imágenes foráneas, a pesar de las enconadas luchas políticas de las que participaban o de que muchos de ellos reconocieran su parte de verdad en los juicios extranjeros. Sobre todo, existió una cierta comunión a la hora de afirmar que era a los españoles, y no a los extranjeros, a quienes correspondía sancionar y delimitar los rasgos propios de España y de sus habitantes (Andreu Miralles 2016: 118).

Dado que la figura del Tempranillo suponía en sí misma una de las cuestiones que más habían llamado la atención de los escritores extranjeros sobre España — aparte de Merimée, recordemos el citado libro de Richard Ford-, un autor como Fernández y González, en tanto que es consciente de ello, querrá hacer de alguna manera una réplica a todas las visiones europeas, y ofrecer, como alternativa, otra puramente española y presuntamente "más auténtica"; así, la tradición oral de la que afirma beber al final de la obra serviría de refuerzo a afirmaciones tan contundentes como la siguiente:

Nosotros no nos hemos propuesto ocuparnos más que de la vida de azares del célebre bandido, cuyas noticias debemos a un manuscrito del escribano don Fructífero, administrador y testaferro de José María, que nos ha proporcionado uno de los nietos del susodicho escribano.

Este manuscrito había permanecido olvidado, y gracias a él nosotros sabemos de muy buena tinta los sucesos íntimos de José María, que todo el mundo ha ignorado hasta ahora que nosotros los damos a la luz.

Los que hayan creído que nosotros en este libros nos íbamos a ocupar de ternejaladas y aventuras de camino real, siempre iguales, han incurrido en un error.

Al hombre le da a conocer su corazón, no las faenas del oficio.

Si José María no hubiera hecho en este mundo otra cosa que robar a mano armada, su nombre no hubiera llegado a tener la celebridad que alcanza, y que ha llegado hasta el punto de que sobre él se escriba una ópera, que es muy estimada en los principales teatros de Europa. 
Pero desgraciadamente, el autor del libreto no conocía el manuscrito de que nosotros disponemos, y ha hecho un José María a la italiana, que nada tiene de común con nuestro bandido (v. 2, 353).

Nuestro autor descree por completo de las visiones que el extranjero haya podido configurar sobre el Tempranillo, por considerarlas falaces o ficticias, y como alternativa ofrece una versión presuntamente más "realista", porque se apoya, aparte de en el testimonio oral de uno de su cuadrilla, en un supuesto manuscrito del que no hemos encontrado más referencias fuera de esta novela. La intención, en cualquier caso, es evidente: el José María que aquí aparece es el "real”; sus contrapartes en Europa, en cambio, serían ficticias.

Una insistencia en el realismo y en lo veraz de lo tocante al Tempranillo vuelve a aparecer tras referir la muerte de José María: "Nosotros deploramos no poder dar a nuestros lectores una situación más dramática y con más accidentes de la muerte de José María; pero faltaríamos a la verdad. José María murió de este modo, asesinado por el Barberillo en el cortijo de la Alameda, y no podemos faltar a la historia" (v. 5, 163-164). Fijado esto, la referencialidad de esta novela desde luego queda pretendida, por lo que quizá, a partir de aquí, algunos lectores - $-\mathrm{y}$, como hemos visto, incluso algunos historiadores - tomaran por cierto mucho de lo narrado.

Autores como Merimée, a quien Fernández y González había leído y conocía sobradamente ${ }^{10}$, aprovechaban figuras como las del Tempranillo para atacar España y presentar dicho país como una nación retrasada, más salvaje y menos civilizada (Andreu Miralles 2016: 87-113). Defender la figura de José María implicaba, por ello, una defensa de su propio país; hay, así, un intento por dignificarla a toda costa, lo que probablemente hubiera supuesto una criba en los testimonios orales que nuestro autor podría haber recabado.

Encontramos, por ello, fragmentos como en el que José María afirma lo siguiente: "Yo también soy cristiano y de los buenos" (v. 2,

10 En su novela Men Rodríguez de Sanabria cita la Historia de don Pedro de Castilla de Merimée (Fernández y González 1853: 315n-316n). 
24). El hecho de estar fuera de la ley no habrá de impedir, en modo alguno, que la fe cristiana continúe sin ningún tipo de relajamiento; la religión, en este punto, impide al Tempranillo arrastrarse hasta el barbarismo absoluto planteado por Merimée. Pasajes como el siguiente convierten al bandolero en una suerte de paladín de la cristiandad:

El fraile, que era muy buen orador, y muy docto, y a más de esto muy buen hombre, estimulado con la idea de que podía ganar para el cielo todas aquellas almas extraviadas arrebatándoselas al demonio, les enderezó un sermón, de tal manera metafísico y hasta tal punto nutrido de textos latinos, que no había más que pedir.

Pero no era aquel el lugar de este género de elocuencia.

Los bandidos no entendían una sola palabra de lo que el fraile decía, y a cada latinajo les retozaba la risa en el cuerpo; pero se contenían por miedo a José María.

Pero, en fin, uno de ellos, un gitano, el Lechuzo, que estaba junto a José María, y que desde media hora antes se mordía los labios para contener la risa, no pudo al final aguantar más, y soltó una carcajada tan estrepitosa, tan burlona y tan insolente, que el mercenario se detuvo escandalizado, y aun pudiéramos decir que irritado, si no nos pareciese mal hablar de la irritación de un sacerdote, que por su carácter debe tener una gran mansedumbre.

Pero instantáneamente la expresión de indignación del fraile se cambió en una expresión de terror.

Se había oído un pistoletazo y una especie de rugido de fiera.

José María, indignado de la irreverencia del Lechuzo, y sobre todo irritado por el atrevimiento de burlarse de una cosa que él había dispuesto, se había arrancado un pistolete del cinto y le había disparado, levantando la tapa de los sesos al Lechuzo, que cayó lanzando un rugido de agonía, un rugido de fiera (v. 2, 388-389).

Muy lejos queda aquí el pirata de Espronceda, que afirma no tener patria, ley ni Dios; aunque el Tempranillo no reconozca la autoridad de Fernando VII, sigue admitiendo la divina por encima de lo demás - más adelante insiste en ello al afirmar "yo no tengo más señor que el Dios del cielo” (v. 3, 420)—, y más incluso que 
otros bandidos sobre los que tiene autoridad; tanto es así, que dispara contra aquel que no parezca tomársela suficientemente en serio. Su carácter sigue siendo muy violento, pero que actúe así por conformidad con una ley implica una distancia con la barbarie total que le atribuía Merimée.

Por otra parte, recordemos que esta obra procura no solo mostrarnos al Tempranillo en su faceta como bandolero, sino también ofrecernos una visión completa de su vida, incluyendo su última época al servicio del rey. Esta última será, de hecho, aprovechada para intentar dignificarlo aun más, e incidir sobre todo en el servicio a la sociedad que prestó durante sus últimos días:

Sabíase además que en Andalucía, porque no podía menos de saberse, puesto que la manera de haberse indultado José María había causado gran ruido, que los del escuadrón franco de Protección y Seguridad pública de Andalucía eran ni más ni menos que los bandidos que poco antes aterraban aquella comarca; pero si antes habían causado terror, desde el momento en que se habían puesto bajo las leyes, inspiraban mucha más confianza que la que hubiera inspirado un escuadrón que se hubiera formado con gente honrada.

Se sabía que esta gente de José María estaba acostumbrada, bajo las órdenes de su capitán, a tener moderación con todo el mundo, a no meterse con nadie y a respetar todo lo que era respetable, menos el dinero del prójimo.

Quitado este peligro, porque en vez de ladrones se habían hecho agentes de la ley, cualquiera que encontraba a uno de estos muchachos se sentía seguro, como sucede ahora cuando se ve el sombrero galoneado de blanco de la Guardia civil (v. 4, 25).

El autor plantea que, aunque todo el mundo sabía que ese "Escuadrón franco de protección” tenía sus orígenes en el bandidaje, no por ello las personas tienen una impresión peor; por el contrario, son conscientes de que incluso siendo bandidos el Tempranillo los había inclinado a la "moderación", y ahora su sola presencia hacía a la población sentirse tan segura como más adelante se sentiría con la Guardia Civil. 
No solo eso: cuando José María entra al servicio de Fernando VII, muy pronto despierta simpatías hacia ese monarca y comienza a tener el mejor concepto imaginable de este, a quien no duda en defender. Para poder comprender esto correctamente, debemos tener presente la ideología absolutamente monárquica de nuestro autor, ya señalada por Cantos Casenave (2018: 34). Solo entonces explicamos que ponga estas afirmaciones en boca del Tempranillo:

Que la verdad es que si yo no la he armado con el rey, no ha sido porque haya tenido miedo, porque yo no temo a nadie: ha habido un poco de prudencia por la Consuelo; pero más que todo es que me gusta ese señor, que es muy llano, que es muy sencillo, que es muy campechanote, y que no deja meter la cuchara, y que cuando uno quiere meter la conversación por un lado que a él no le gusta, la echa por otro sin que le sienta; en fin, Narizotas es un buen mozo, y es lástima que ahorque gente y persiga por opiniones políticas a nadie, que por eso le llaman tirano y no le quieren: a ese hombre le podía adorar todo el mundo; en fin, cada uno hace lo que le parece; cada alma en su palma, y vamos andando (v. 4, 407).

De esta manera, hay a un mismo tiempo una apología tanto al Tempranillo como a Fernando VII: al primero, por mostrárnoslo capaz de atenderse a la autoridad de un rey con el que llega a simpatizar, todo ello bajo una visión del mundo monárquica; al segundo, por ser admirado por el primero a pesar de los fallos que José María le reconoce.

Fernández y González desarrolla, en definitiva, una imagen del Tempranillo que muy poco tiene que ver con la habida en Merimée; es este un bandolero mucho más civilizado, racional y cristiano, carente de la maldad atribuida, y cuyos orígenes deberían buscarse en buena medida en la tradición oral a la que nuestro autor pudo acceder por vía del mencionado informante $u$ otros similares.

\section{El trasfondo moral de la novela}

Pero por mucho que la literatura oral haya podido influir en esta obra -en lo relativo a la presunta biografía del "Veneno" o a la 
imagen del Tempranillo-, hay una cuestión muy concreta que debería ser atribuida en su totalidad a nuestro autor, esto es, la intencionalidad moral de la obra. Más allá de que sea cierto o no lo narrado, o de las fuentes que haya podido manejar, los hechos están dispuestos de tal manera que facilitan una reflexión moral bastante explícita, la cual atañe, por un lado, tanto al bandolerismo como tal, como concepto, y por otra parte a lo tocante ya no a la vida del Veneno como tal, sino a las de todos aquellos que, como él, prefieren evitar la tranquilidad y la paz a fin de buscar aventuras al otro lado de la ley. En lo tocante a la reflexión sobre el bandidaje, queda sintetizada en el siguiente fragmento:

Esto era enorme, y debe parecer extraordinariamente inverosímil a los que no sepan cómo se considera el bandidaje en Andalucía.

Pero creemos que no tenemos que esforzarnos gran cosa para curar de su extrañeza a aquellos de nuestros lectores que encuentren esta conducta contradictoria, tal vez irreligiosa, en un bandolero, que por sus crímenes está completamente fuera de las leyes divinas y humanas.

En Andalucía, el bandidaje ha sido, es y será hasta que Dios quiera, hasta que la civilización penetre en sus campiñas, una profesión, una manera de vivir que la mayoría de la población andaluza acepta como lo más natural del mundo.

En Andalucía es muy antiguo el socialismo, y esto proviene de la soberbia ingénita de los andaluces, determinada acaso por lo ardiente del clima.

Los andaluces sufren mal la servidumbre y la explotación de los grandes propietarios; son generosos y valientes, impresionables y soñadores, irritables y aventureros.

El duro trabajo del campo que los mantiene en la miseria y los abusos de los propietarios, que aunque no los dejan perecer los tienen reducidos a la situación de siervos de la gleba, producen su rebeldía contra la sociedad, su protesta enérgica, y los lanza a los caminos a combatir con las leyes. 
Se tiene además a gala porque el bandidaje es una ocasión perpetua de demostrar el valor, y una de las cosas que más ama el andaluz es permanecer valiente, $y$ lo es.

Es un error gravísimo creer que el andaluz no pasa más allá de la fanfarronada.

La lucha tenaz que hoy sostiene el bandido andaluz con la guardia civil es una prueba de ello: se ha usado con ellos una conducta de exterminio, como lo prueban las grandes acusaciones que se han hecho al ministerio de la Gobernación en la prensa y en la tribuna, y sin embargo, el bandidaje continúa terrible y audaz, más irritado hoy tal vez que en los tiempos de José María, y también menos legendario, y por lo tanto más terrible.

Aquello es la miseria de un habitante pobre de una grande y riquísima provincia; aquello es una protesta desesperada del proletariado andaluz, aquello es una revolución, que no tiene carácter político en la forma, pero sí en el fondo.

Suponed que esos bandidos que salen al camino a arrebatar a la guardia civil, batiéndose con ella, sus compañeros presos, se encubriesen bajo una bandera política; la fermentación de Andalucía tendría entonces un carácter terrible; y sin embargo, ellos desdeñan la política; ellos, soldados del socialismo, lo practican sin reconocerlo, secuestran al proletario y le arrancan violenta y criminalmente el pan que necesita para sus hijos, y el socialismo, monstruo de nuestros días, creado por la injusticia y el abuso, no aparece allí, porque su acción no sale de la esfera vulgar (v. 2, 26-27).

A partir de una visión del mundo explícitamente determinista plantea que el fenómeno del bandidaje está estrechamente ligado a las características geográficas y ambientales de Andalucía; tras establecer esto, su reflexión pasa a convertirse de manera paulatina en una sátira, no demasiado disimulada, hacia el socialismo.

La crítica pasa por hacer una equivalencia entre bandidos y socialistas partiendo de que ambos "roban a los ricos para dárselo a los pobres”. De este modo, se dignifica el bandidaje al tiempo que se echa por tierra al socialismo —o al menos, se intenta-; todo rasgo criminal atribuido a los bandoleros le es adjudicado a los socialistas, 
y viceversa, todo rasgo positivo por el cual se pueda defender al socialismo, como el cuidado de los pobres, también queda atribuido a los bandoleros.

Pero esta perspectiva, de carácter político, no es la que fundamentalmente predomina en la obra, cuyo objeto central, como ya se ha dicho, no es el bandidaje en sí, sino la vida del teniente Veneno. Para poder comprender qué conclusión moral se puede extraer de esto otro, el siguiente texto resulta iluminador:

Para los liberales españoles, la identidad política de sus ciudadanos (y su masculinidad) debía descansar sobre su condición de padres de familia. Para ser reconocidos como tales los ciudadanos debían probar su capacidad para formar y gobernar un hogar. El matrimonio, producto de la unión por la inclinación entre un hombre y una mujer, debía ser el corazón de la república y de la sociedad, y el garante de la moralidad nacional. En tiempos de guerra y revolución, el amor a la independencia y a la libertad, o una violencia varonil, eran deseables siempre que fueran encauzados de manera correcta. Ahora bien, en tiempos de paz, cuando de lo que se trataba era de construir una nación moderna y respetable, los liberales se plantearon la necesidad de remediar esta supuesta propensión de los españoles hacia un tipo de masculinidad mal entendida, que en la prensa y la literatura de la época encarnaba el tipo del calavera. [...] Al fin y al cabo, la virilidad y la rebeldía eran en la Europa decimonónica elementos fundamentales en el aprendizaje y reconocimiento de la masculinidad. La vida doméstica que prescribía para los hombres la nueva respetabilidad liberal, podía percibirse incluso como un peligro para dicha masculinidad. [...] La tensión entre dos discursos contradictorios se resolvía considerando las calaveradas vicios de juventud hasta cierto punto necesarios en el aprendizaje de la masculinidad (Andreu Miralles 2016: 216-218).

Tal es, exactamente, lo que ocurre con el teniente Veneno. Pese a que no podamos hablar de una historia real, y al margen de que hubiera podido basarse nuestro autor en mayor o menor medida en un informante de tradición oral, la historia de Luis de Céspedes es, al fin y al cabo, una historia de "aprendizaje" de ese nuevo tipo de masculinidad que se procuraba perfilar en la España decimonónica. 
La sed de aventura, los desvaríos amorosos y el enfrentamiento con la ley, en el conjunto de la vida del Veneno, no son más que una etapa a superar; finalmente, las mutilaciones que este personaje sufre hacen que forzosamente tenga que redimirse y enderezar su conducta hasta poder llegar a ser un cabeza de familia adecuado, dispuesto a serle fiel a María.

Bien es cierto, no obstante, que nuestro autor ofrece cinco larguísimos tomos en los que el lector puede recrearse largo y tendido con estas "experiencias de aprendizaje", que son interrumpidas bruscamente con las mutilaciones que dan fin a la obra, las cuales fuerzan al protagonista a "madurar" de una manera violenta e inevitable.

\section{Referencias bibliográficas}

Álvarez Barrientos, Joaquín y Pilar García Mouton

1986 “Bandolero y bandido. Ensayo e interpretación”. Revista de Dialectología y Tradiciones Populares. XLI, separata.

Andreu Miralles, Xavier

2016 El descubrimiento de España. Mito romántico e identidad nacional. Barcelona: Taurus.

Ávila Granados, Jesús

2008 El libro negro de la historia de España. Barcelona: SWING.

Blasco IbáÑez, Vicente

1982 Los mejores artículos. Ed., Paul C. Smith. Valencia: Editorial Prometeo.

Cantos Casenave, Marieta

2018 "La buena madre, de Manuel Fernández y González. Representaciones literarias del poder femenino en tiempos convulsos”. Crítica hispánica. 40, 2, 31-52.

Cruz Casado, Antonio

2001 "El espejo infiel: una aproximación al bandolero romántico y su reflejo en la literatura española”. Iberoamericana, 8, 31, 137-148. 
Cruz Casado, Antonio

2015 Bandoleros en Sierra Morena (Ventas y bandidos en textos literarios decimonónicos. Consultado: 7 de octubre de 2020. $<$ https://www.academia.edu/34121947/Antonio_Cruz_ Casado_Bandoleros_en_Sierra_Morena._Ventas_y_bandidos_en_textos_literarios_decimon\%C3\%B3nicos.pdf>

Fernández Cuesta, Nemesio

1864 “Don Manuel Fernández y González. Apuntes biográficos”. El museo universal. VII, 24, 188-190.

FERNÁNDEZ Y GONZÁLEZ, Manuel

1851 El condestable don Álvaro de Luna. Novela histórica original. Madrid: Gaspar y Roig.

FERNÁNDEZ y GONZÁLEZ, Manuel

1853 Men Rodríguez de Sanabria (Memorias del tiempo del rey don Pedro el Cruel). Novela histórica original. Madrid: Gaspar y Roig.

FERNÁNDEZ y GONZÁLEZ, Manuel

1863 Los siete niños de Écija. Madrid: Don Miguel Prats, Editor.

FERNÁNDEZ Y GONZÁLEZ, Manuel

1874 El rey de Sierra Morena. Aventuras del famoso ladrón José María. 5 volúmenes. Madrid: Imprenta de Santos Larxé.

FERreras, Juan Ignacio

1979 Catálogo de novelas y novelistas españoles del siglo XIX. Madrid: Cátedra.

FORD, Richard

1846 Gatherings from Spain. Londres: John Murray Almemarle Street.

Hernández Girbal, Florentino

1931 Una vida pintoresca: Manuel Fernández y González. Biografía novelesca. Madrid: Biblioteca Atlántico.

López-Burgos del Barrio, María Antonia

2012 "La Alpujarra en la literatura de viajes: Gerald Brenan y otros precursores". The Grove. Working Papers on English Studies. 19, 33-50. 
MaCHAdo, Manuel

1981 La guerra literaria. Eds., María Pilar Celma Valera y Francisco J. Blasco Pascual. Madrid: Narcea S. A. de Ediciones.

Merimée, Prospero

1891 Carmen. Barcelona: López Editor-Librería Española.

Moll, Nora

2002 "Imágenes del «otro». La literatura y los estudios interculturales". n Introducción a la literatura comparada. Ed., Armando Gnisci. Barcelona: Crítica, 347-389.

Monguió, Luis

1951 "Crematística de los novelistas españoles del siglo XIX". Revista Hispánica Moderna. XVII, 111-127.

Ortega Serrano, Antonio

2010 “El Tempranillo» (En la literatura y la leyenda)”. Crónica de Córdoba y sus Pueblos. XVI, 219-238.

Palacio Valdés, Armando

1878 Los novelistas españoles. Semblanzas literarias. Madrid: Casa Editorial de Medina.

Pérez Galdós, Benito

2004 Prosa crítica. Eds., José-Carlos Mainer y Juan Carlos Ara Torralba. Madrid: Espasa-Calpe.

Quirós y PÉrez, Constancio Bernaldo de

1992 Bandolerismo y delincuencia subversiva en la baja Andalucía.

Sevilla: Renacimiento.

Quirós y Pérez, Constancio Bernaldo de y Luis Ardilla

1973 El bandolerismo andaluz. Madrid: Turner.

ROMERo TOBAR, Leonardo

1976 La novela popular española del siglo XIX. Madrid: Editorial Ariel.

Recepción: 12/10/2020

Aceptación: 14/01/2021 